\title{
Engineering-medicine as a transforming medical education: A proposed curriculum and a cost-effectiveness analysis
}

\author{
Lawrence S Chan* \\ University of Illinois College of Medicine, 808 S Wood, Suite 380, Chicago, IL, USA
}

\begin{abstract}
The current US medical care system faces many challenges. While the cost is very high, the overall quality is disappointing, particularly in access and equity. Facing an increasing demand of medical care, efforts to improve medical care in fulfilling the triple aims of "better care, better health, and lower cost" called for by the National Academy of Medicine are at the front and center in the healthcare debate. In this paper a transformation of current medical education by incorporating engineering principles into traditional medical teaching is introduced along with a proposed curriculum, followed by an economic evaluation of such transforming educational changes. A brief cost-effectiveness analysis on such an engineering-medicine education, from a societal perspective and under a set of assumptions, results in a positive cost-effective outcome. Therefore, on health economic grounds, an engineering-medicine education could be implement in a small subset of students as a proof of concept study.
\end{abstract}

\section{Introduction to Engineering-Medicine, a Transforming Medical Education}

Before we discuss a transformation of medical education, we should first delineate briefly the reasons for the change and define the parameters for improvement. For that, we start with the current status of medical practice and medical education.

First, there is the high cost of healthcare in the US. Measuring the healthcare spending world-wide, it has been determined that US has the highest per capita expenditure in healthcare [1]. Second, there is the healthcare inefficiency in the US. Despite its high cost, US healthcare efficiency has been ranked as one of the lowest among the wealthiest countries [2]. Specifically, the access, efficiency, and equality of healthcare for US people were ranked last or near last among the developed nations [2].

Regarding the current curriculum of medical education, there is a lack of up-to-date training in technology utilization [3-8], as well as a need to improve efficiency [2]. Accordingly, there have been calls for healthcare and medical education reforms by the nation's medical education leaders. Realizing the problems of high cost and low overall quality of healthcare, the National Academy of Medicine (formerly Institute of Medicine) has called the medical professions to fulfill a triple aim of goals [9].

- Better care: Improve access and equity of care [9].

- Better health: Since better care does not necessarily lead to better health, the National Academy of Medicine emphasizes this point to encourage medical professions to think about other determinants towards the ultimate health outcome, not just the intermediate step of healthcare [9].

- Lower costs: Faced with increasing costs, the National Academy of Medicine is urging medical professions to think of ways to improve efficiency to reduce the cost of healthcare delivery [9].
Recognizing the essential roles of medical education in fulfilling the triple aims called for by the National Academy of Medicine, American Medical Association has called for reform by the medical educators, with emphasis on the following areas [10].

- Increase technology training

- Increase team-approach training

- Increase systems practice training

That leads to the consideration of medical education reform through a novel engineering-medicine curriculum. Since the characteristic engineering education goals are efficiency, team-based, systems-approached, and technology-oriented, it has been proposed that incorporating engineering principles is one possible way to reform medical education [11]. The argument supporting such reform are that engineering education dove-tails with medical education $[11,12]$ and that the potential impact of Engineering-Medicine education in future medical practice could be significant [11]. The National Academy of Medicine also recognized the potential role of engineering in healthcare transformation and has called for the partnership between engineering and medicine. As early as 2005, the Institute of Medicine (now the National Academy of Medicine) has encouraged the building of a partnership between engineering and medicine to help in solving healthcare delivery challenges [13]. While it is prudent to consider training established physicians in incorporating engineering principles

*Correspondence to: Lawrence S Chan, University of Illinois College of Medicine, 808 S Wood, Suite 380, Chicago, IL USA, Tel. (312) 996-6966; Fax. (312) 996-1188; E-mail. Larrycha@uic.edu

Key words: cost-effectiveness analysis, engineering, efficiency, transforming

Received: April 15, 2018; Accepted: April 23, 2018; Published: April 30, 2018 
in their practices, changing physician behavior is hard to accomplish in a sustained manner [14]. Medical students, on the other hand, being at a knowledge-acquiring stage of their lives, would likely be more open to accepting these new ideas. Thus, incorporating engineering concept at the medical school level would be the optimal solution. A few medical educators have accepted the concept of incorporating engineering principles into medical education. An EnMed program established by the Texas A \& M University will start its new medical education program in 2017 [15] and a new engineering-based medical school will start its inaugural class in 2018 [16]. The goal of this paper, is, therefore, to encourage the development of more such programs by proposing an engineering-medicine curriculum and analyzing its cost-effectiveness from a societal perspective.

\section{Defining the Rationale and Methods of Cost-Effectiveness Analysis on Engineering-Medicine Education}

Having stated the potential impact of Engineering-Medicine education in the future medical practice, we now turn to the next question: Can we determine if such education is cost-effective from the health economic perspective?

Let us first define the key elements of this particular cost-effectiveness analysis. Cost-effectiveness analysis in healthcare is a scientific method conducted in a systematic manner with the purpose to assist education leaders in making logical decisions on interventions or programs meant to improve health $[17,18]$. Such methods will help healthcare managers focus on what works and reduce the chance of decision error or waste. In short, the "whole point of cost-effectiveness, after all, is to examine the optimal course of action when there is considerable uncertainty" [18]. Since uncertainty is one element of cost-effectiveness analysis, there is no absolute guarantee for its outcome. Accordingly, the key elements of cost-effectiveness analysis include the following [17, 18]:

- Perspective: Before going about the cost-effectiveness analysis, it is imperative that the perspective of the analysis is delineated, whether it is from the perspective of the institution or from the perspective of the society, since the benefits to these entities are different. For this project, the perspective will be from the society as a whole.

- Competing alternative: Although this point seems to be obvious, it needs to be clarified. To make a decision on a new intervention or program, we need to compare both the cost and effectiveness of the new one with that of the existing one (or the conventional or traditional one). For this paper, the competing alternative for engineering-medicine education is the traditional medical education.

- Determine the costs: It is essential that the new intervention or program will not be cost prohibitive even if it is more effective. In this project, the costs used for comparison will include the physical facility, IT infrastructure and maintenance, faculty, and staff. We will estimate such costs in dollar terms.

- Determine the effectiveness: This point is front and center of the analysis, as the new intervention or program should be at the minimum as effective as the existing one, if not more effective. The obstacle here is that there is no school of engineering-medicine currently in operation. In the absence of such data, the best effort is made to collect existing studies analyzing interventions or programs utilizing engineering principles that resulted in improving healthcare effectiveness. The assumption is that these interventions or programs, if incorporated into medical education, would have the similarly effective outcomes. We will define the effectiveness as cost saving for the healthcare system in dollar terms.
- Calculate the Cost-effectiveness Ratio: Once the cost and effectiveness are determined, this ratio will provide substantial help to the decision-making process. The formula of this ratio is the difference of cost (between the new one and the competing alternative) divided by the effectiveness (between the new one and the competing alternative). Since both cost and effectiveness are determined in dollar terms, a ratio smaller than one (1.0) would indicate that the increase of effectiveness outweighs the increase of cost, thus indicating the program in consideration is cost-effective.

- One-way sensitivity analysis: In this analysis, we will test the sensitivity of projected outcomes when we vary the input assumptions (one variable) in different directions.

- Two-way sensitivity analysis: Finally, we will test the sensitivity of projected outcomes by varying both the cost side and the effectiveness side of the equation.

\section{Curriculum Frame Works for Engineering-Medicine Education}

Before we proceed to the actual cost-effectiveness analysis, it is important that we determine the parameters for such analysis. Along this line, we should first delineate what an engineering-medicine education will teach the medical students in such a novel curriculum. Towards this end, the following engineering-medicine curriculum, as a supplement, not a substitution, to a traditional medical curriculum, is developed for such analysis. A truly engineering-medicine curriculum, is more than just increase of teaching of technology in medicine, it requires the change of mind-set and approach. "Think like an engineer and act as a physician" is the central aim of engineering medicine. From the time commitment perspective, it is estimated that this engineeringmedicine curriculum would occupy about $25 \%$ of a four-year medical college curriculum, with the remaining (75\%) time spent in the conventional medical curriculum:

\section{Course A. Introduction to Engineering-Medicine}

The learning objective is to familiarize the students with the current state of US healthcare, the call for medical care and medical education reforms by the Institute of Medicine, and the American Medical Association, and the potential role of engineering-medicine in transforming the future medical education.

Expected learning outcomes when students complete the course:

- Understand the current state of medicine and medical education

- Understand the urgency for the call for medical education reform

- Understand Engineering-medicine as an innovation of medical education reform

Method of instruction: Group lectures

Textbook/reading materials:

- Brook RH. Redefining health care systems. Rand. Santa Monica, CA. 2015

- Chan LS. Building an engineering-based medical college: Is the timing ripe for the picking? Med Sci Edu 2016; 26:185-90.

- Topol E. The creative destruction of medicine: How the digital revolution will create better health care. Basic Books. New York, NY. 2013 
Method of assessment: Class discussion participation

\section{Course B. Engineering Principles Overview}

The learning objective is to provide a basic frame work of how engineering works and what are the goals of engineering.

Expected learning outcomes when students complete the course:

- Understand the overall engineering principles

- Understand the distinction between scientific method and engineering method

- Understand the general approach of engineering

Method of instruction: Group lectures

Textbook/reading materials:

- Moaveni S. Engineering fundamentals: An introduction to engineering. $5^{\text {th }}$ ed. Cengage. Boston, MA. 2015

- Kosky P, Balmer R. Exploring engineering: An introduction to engineering and design. 4th ed. Academic Press. San Diego, CA. 2015.

- Blockley D. Engineering: A very short introduction. Oxford University Press. Oxford. UK. 2012

Method of assessment: Closed book examination

\section{Course C. Engineering-Medicine Principles Overview}

The learning objective is to delineate the definition of engineeringmedicine, what its principles are, and what it can contribute to the overall efficiency of health care.

Expected learning outcomes when students complete the course:

- Understand the overall goal of engineering-medicine

- Understand the overall engineering-medicine principles

- Understand the potential contributions of engineering-medicine to overall healthcare

Method of instruction: Group lectures, group discussion

Textbook/reading materials:

- Chan LS. Building an engineering-based medical college: Is the timing right for the picking? Med Sci Edu 2016; 26:185-90.

- Mesko B. The guide to the future of medicine: Technology and the human touch. Webicina Kft.2015

- Topol E. The creative destruction of medicine: How the digital revolution will create better health care. Basic Books. New York, NY. 2013

- Kopach-Konrad R, Lawley M, Criswell M, et al. Applying systems engineering principles in improving health care delivery. J Gen Intern Med 2007; 22(Suppl 3):431-7.

- Reid P, Compton WD, Grossman JH, Fanjiang G. Building a better delivery system: A new engineering/health care partnership. The National Academy Press. Washington, DC 2005

- Belson D. Operations improvement methods: Choosing a path for hospitals and clinics. California Healthcare Foundation. 2010. Los Angeles, CA 2010
- Gill PS. 5 product engineering methods to use in health care management. Managed Care 2013; March: 21-25.

- Watts BV, Shiner B, Ceyhan ME, Musdal H, Sinangil S, Benneyan J. Health systems engineering as an improvement strategy: a case example using location-allocation modeling. J Healthc Qual 2013; 35:35-40.

- Curran ET, Benneyan JC, Hood J. Controlling methicillin-resistant Staphylococcus aureus: a feedback approach using annotated statistical process control charts. Infect Control Hosp Epidemiol $2002 ; 23: 3-8$

Method of assessment: Class discussion participation

\section{Course D. Introduction to Systems Biology}

The learning object is to help students appreciate that the entire human body functions as a large interconnected coordinated system, rather than many small independent systems.

Expected learning outcomes when students complete the course:

- Understand the human body as one interconnected and integrated system

- Understand and able to construct simple computational model

- Understand the concept of quantitative physiology

- Understand various biological signaling mechanisms

- Understand biological transportation \& fluid flow

- Understand bioelectric function

Method of instruction: Group lectures

Textbook/reading materials:

- Alon U. An introduction to systems biology. Chapman \& Hall, Boca Raton, FL 2007

- Ingalls BP. Mathematical Modeling in Systems Biology: An introduction. MIT Press, Cambridge, MA 2013

- Voit EO. A first course in systems biology. 2nd Ed. Garland Science. New York, NY. 2018

- Saltzman WM. Biomedical Engineering: Bridging medicine and technology. 2nd Ed. Cambridge University Press. Cambridge, UK. 2015.

- Klipp E, Liebermeister W, Wierling C, Kowald A. Systems biology: A textbook. 2nd ed. Wiely-VCH. Weinheim, Germany. 2016

Method of assessment: Closed book examination

\section{Course E. Invention \& Innovation}

The learning objectives are to open students' minds to the world of innovation and invention, which are the signature characteristics of engineering, to understand the importance of invention and innovation in building the future medicine, and to guide the students to hands-on real-life projects of medical invention and innovation.

Expected learning outcomes when students complete the course:

- Understand the distinction of invention and innovation

- Understand the importance of invention and innovation in medicine

- Understand the process of invention 
- Understand the process of patent protection for invention

- Participate in a real-life invention

Method of instruction: Group lectures, group discussion, individual tutor, project

Textbook/reading materials:

- Kennedy P. Inventology: How we dream up things that change the world. Harcourt Publishing. New York, NY. 2016

- Kaufman SB, Gregoire C. Wired to create: Unraveling the mysteries of the creative mind. Perigee. New York, NY, 2015

- Pacey JA. Life-changing medical invention: Build a successful enterprise and a new world. Advantage. Charleston, SC. 2015.

Method of assessment: Final individual project evaluation

\section{Course F. Systems Integration}

The learning objectives are to familiarize the students with the engineering concept of system integration, to help the students in discovering potential use of integration for improving healthcare delivery, and to guide the students in applying integration in real-life medical encounters.

Expected learning outcomes when students complete the course:

- Understand the engineering concept of system integration

- Understand the usefulness of engineering integration in medicine

- Design an integration for a real-life medical encounter

Method of instruction: Group lectures, group projects

Textbook/reading materials:

- Griffin PM, Nembhard HB, DeFlitch CJ, Bastian ND, Kang H, Munoz DA. Healthcare systems engineering. John Wiley \& Sons. Hoboken, NJ. 2016

- La Penna AM. Medical staff integration: Transaction and transformation. CRC Press. Boca Raton, FL 2015

- Alper J and Grossman C. Integrating research and practice. Institute of Medicine of the National Academies. National Academies Press. Washington, DC 2015

Method of assessment: Group project evaluation

\section{Course G. Efficiency}

The learning objectives are to familiarize the students with the engineering concept of efficiency and the importance of efficiency in healthcare delivery, and to guide the students for their individual projects in improving real-life medical encounters.

Expected learning outcomes when students complete the course:

- Understand the importance of the engineering concept of efficiency.

- Be able to apply the engineering concept of efficiency in a real-life medical encounter

Method of instruction: Group lectures, individual project

Textbook/reading materials:

- Dahl OJ. Think business! Medical practice quality, efficiency, profits. 2nd Ed. Greenbranch Publishing. Williamsport, PA. 2016
- Kenney C. Transforming health care: Virginia Mason Medical Center's pursuit of the perfect patient experience. CRC Press. New York, NY. 2011

- Begley CE, Lairson DR, Morgan RO, Rowan PJ, Balkrishnan R. Evaluating the healthcare system: Effectiveness, efficiency, and equity. 4th Ed. Health Administration Press. 2013

Method of assessment: Individual project evaluation

\section{Course H. Problem-solving}

The learning objectives are to familiarize the students the engineering method of problem-solving, and to guide the students in their group projects of solving real-life problems in healthcare encounters.

Expected learning outcomes when students complete the course:

- Understand the engineering problem-solving cycle

- Understand the engineering problem-solving matrix

- Be able to utilize engineering principles to solve a real-life medical encounter

Method of instruction: Group lectures, group projects

Textbook/reading materials:

- Etter DM. Engineering problem solving with C. Pearson Education. 4th Ed. 2012.

- Butterfield J. Problem solving and decision making. 2nd Ed. Cengage. Boston, MA. 2013

- Sharp JJ. Methodologies for problem solving: An engineering approach. The Vocational Aspect of Education. 1991; 114:147-57.

Method of assessment: Group project evaluation

\section{Course I. Design \& Optimization}

The learning objectives are to familiarize the students with the engineering principle of "design \& optimization" and the potential application of this principle in medicine, and to guide the students in their group projects for design and optimization of real-life medical encounters.

Expected learning outcomes when students complete the course:

- Understand the engineering concept of design and optimization

- Understand the potential role of engineering design and optimization in medicine

- Be able to apply engineering design and optimization in a real-life medical problem

Method of instruction: Group lectures, group projects

Textbook/reading materials:

- Ganguli R. Engineering optimization: A modern approach. CRC Press. Boca Raton, FL. 2012

- Arora RK. Optimization: Algorithms and applications. CRC Press. Boca Raton, FL. 2015

- Karsnitz JR, O’Brien S, Hutchinson JP. Engineering design: An introduction. Cengage. Boston, MA. 2012

Method of assessment: Group project evaluation 


\section{Course J. Precision}

The learning objectives are to familiarize the students with the engineering principle of precision and the importance of precision in medical practice, and to guide the students in their individual projects in applying precision-medicine principles to real-life medical encounters.

Expected learning outcomes when students complete the course:

- Understand the engineering concept of precision

- Understand the importance of precision-medicine in the next generation of medical practice

- Be able to utilize precision-medicine in a real-life medical problem Method of instruction: Group lectures, individual project

Textbook/reading materials:

- McCarthy JJ. Mendelsohn BA. Precision medicine: a guide to genomics in clinical practice. McGraw-Hill. New York, NY. 2017

- Ginsburg GS, Willad HF. Genomic and precision medicine: Foundations, translation, and implementation. 3rd Ed. Academic Press. San Diego, CA. 2016

- Cullis P. The personalized medicine revolution: How diagnostic and treating disease are about to change forever. Greystone Books. Vancouver, BC, Canada. 2015

Method of assessment: Individual project evaluation

\section{Course K. Advanced Biotechnology}

The learning objectives are to familiarize the students with emerging biotechnology developments and their potential roles in future medical practices.

Expected learning outcomes when students complete the course:

- Understand the importance of biosensors in medicine

- Understand structure and function of various biomaterials

Nanobiotechnology

3-D printing

Artificial organs

- Understand the utilization of biomechanics

- Understand the medical application and limitation of robotics

Method of instruction: Group lectures

Textbook/reading materials:

- Saltzman WM. Biomedical Engineering: Bridging medicine and technology. 2nd Ed. Cambridge University Press. Cambridge, UK. 2015.

- Zhang LG, Fisher JP, Leong KW. 3D bioprinting and nanotechnology in tissue engineering and regenerative medicine. Academic Press. San Diego, CA. 2015

- Schweikard A, Ernst F. Medical robotics. Springer. Switzerland. 2015 Method of assessment: Closed book examination

\section{Course L. Biomedical imaging}

The learning objectives are to familiarize the students with scientific principles, medical applications, diagnostic limitations, and potential side effects of various biomedical imaging techniques. The aims are to train the future physicians to not only able to have the knowledge of what technique to use under certain circumstances, but also have the understanding of why each technique is suitable for particular conditions and their limitations.

Expected learning outcomes when students complete the course:

- Understand the principle, application, and limitation of various imaging technology:

Ultrasound Imaging

Computer Tomography (CT) Scan

Magnetic Resonance Imaging (MRI)

Positron Emission Tomography (PET) Scan

Photoacoustic (Optoacoustic) Imaging

Mass Spectrometry Diagnostic Imaging

- Understand quantitative Image Analysis

Method of instruction: Group lectures

Textbook/reading materials:

- Saltzman WM. Biomedical Engineering: Bridging medicine and technology. 2nd Ed. Cambridge University Press. Cambridge, UK. 2015.

- Cherry SR, Badawi RD, Oi J, ed. Essentials of in vivo biomedical imaging. CRC Press. Boca Raton, FL. 2015

- Diaspro A, van Zandvoort MAMJ. Super-resolution imaging in biomedicine. CRC Press. Boca Raton, FL 2017

- Wang, LV. Photoacoustic imaging and spectroscopy. CRC Press. Boca Raton, FL, 2017

Method of assessment: Closed book examination

\section{Course M. Big Data Analytics and Statistics}

The learning objectives are to familiarize the students with what Big Data is, what potential roles does Big Data have to improve the health care, and what are the challenges and road blocks that could prevent Big Data from fulfilling its potential. In addition, a brief lesson of statistics will be taught to help the students in understanding its role in healthcare.

Expected learning outcomes when students complete the course:

- Understand the key element makeup of Big Data

- Understand the potential usefulness and limitation of Big Data in medicine

- Be able to perform common statistical analysis

Method of instruction: Group lectures, individual problem sets

Textbook/reading materials:

- Yang H, Lee EK. Healthcare analytics: From data to knowledge to healthcare improvement. 1st Ed. John Wiley \& Sons. Hoboken, NJ. 2016

- Schmuller J. Statistical analysis with Excel for dummies. John Wiley \& Son. Hoboken, NJ 2016 
- Render B, Stair RM, Hanna ME, Hale TS, Badri TN. Quantitative analysis for management. Pearson. Uttar Pradesh, India. 2016

Method of assessment: Individual problem set evaluation

\section{Course N. Health Quality Management}

The learning objectives are to familiarize the students with the engineering principle of quality management and the importance of quality in health care, and to guide the students in their group projects of conducting quality management in real-life medical encounters.

Expected learning outcomes when students complete the course:

- Understand the engineering concept and function of quality management

- Understand the importance of quality management in medicine

- Understand the principle of healthcare quality management

- Understand the principle and applications of various methods healthcare quality management: SMART goal setting, Fishbone diagram, Lean method, Six Sigma method, statistical control chart method, and PDSA method.

- Ability of utilizing engineering quality control in real-life medical practice

Method of instruction: Group lecture, group project

Textbook/reading materials:

- Gawande A. The checklist manifesto: How to get things right. Metropolitan Books. New York, NY. 2010

- Makary M. Unaccountable: What hospitals won't tell you and how transparency can revolutionize health care. Bloomsbury Press. New York, NY. 2013

- Montgomery DC. Introduction to statistical quality control. 7th Ed. John Wiley \& Sons. Hoboken, NJ. 2013

- Spath PL. Introduction to healthcare quality management. 3rd Ed. Health Administration Press, Chiago, IL 2018

Method of assessment: Group project evaluation

\section{Course O. Ethical perspectives}

The learning objectives are to familiarize the students with ethical considerations of the new Engineering-Medicine curriculum, including the ethical issues of changing curriculum, the ethical issues of compromising quality/safety for the sake of efficiency, the ethical issues of privacy, and the ethical issues of increased utilization of advanced biotechnology.

Expected learning outcomes when students complete the course:

- Understand the ethical consideration of curriculum transformation

- Understand the importance of privacy protection

- Understand the ethical concern of compromising quality \& safety over efficiency

- Understand the ethical concern of increasing technology utilization

- Understand the role of the physician in preventing ethical breaches Method of instruction: Group lectures, group discussion

Textbook/reading materials:
- Morrison EE. Ethics in health administration: A practical approach for decision makers. Third Ed. Jones \& Bartlett. Burlington, MA. 2016.

- Presidential commission for the study of bioethical issues. Bioethics for every generation: deliberation and education in health, science, and technology. Createspace Independent Publishing Platform. 2016

- Gronowicz G. Personalized medicine: Promises and pitfalls. 1st Ed. CRC Press. Boca Raton, FL. 2016

Method of assessment: Closed book examination

\section{Cost analysis}

First, let us delineate our analytical assumptions. For the purpose of this analysis, we will assume the new medical college, regardless if it is an engineering-medicine college or a traditional one, will have an inaugural class size of 50 .

With our assumptions set, the cost data were collected by the following manner:

\section{Facility costs: conventional vs. engineering-medicine}

To estimate the cost for a new medical school education building, we will examine the costs of similar buildings in some recently completed facilities. For example, University of North Dakota, built a new educational building in 2013 with a total of 325,000 square feet space that cost $\$ 125$ Million [19]. Another example is the new educational building of Cooper Medical School of Rowan University which cost $\$ 139$ million, with the capacity of 200,000 square feet to accommodate 100 students per class [20]. Another new medical education building to be completed in 2016 for University of Texas in Rio Grande Valley cost $\$ 54$ million with the capacity of 88,250 square feet, including classrooms, conference rooms, study rooms, faculty offices, simulation center, digital anatomy lab, an auditorium, a library/learning center, and a student lounge [21]. For a new medical school with a projected class size of 50, it is estimated that we need an educational building of 100,000 square feet, sufficient to contain some small class rooms, an auditorium with the size to accommodate 250 attendees (50 students/class X 4 classes +50 faculty and others), some laboratories, and a simulation center, an anatomy lab, as well as some study rooms for students and office spaces for faculty and staff. An estimate of $\$ 80$ million is considered sufficient for a conventional school. Let us further assume that the more technology-intense Engineering-Medicine curriculum will require a facility that is relatively larger and equipped with more advanced instrumentation than the conventional medical college. We will make an assumption that $15 \%$ more a price tag is required for the education building of the engineering-medicine school of the same size, equating to $\$ 92$ million. If we assume a $5 \%$ interest loan amortize the building expense to a 25 -year usage, the annual expense for the medical education building will be $\$ 5,676,196$ and $\$ 6,527,626$, for the conventional and engineering-medicine schools, respectively (Table 1)

\section{Information Technology (IT) costs: conventional vs. engineering-medicine}

Let us also assume that IT cost in the more technology-intense Engineering-Medicine curriculum will require an expense in IT infrastructure and maintenance that is $10 \%$ higher than the conventional medical college. If we set the annual IT cost for conventional school to be $\$ 500,000$, the corresponding cost for engineering-medicine school will be $\$ 550,000$ (Table 1 ). 
Table 1. Annual Cost Comparison Between Conventional and Engineering-Medicine School

\begin{tabular}{|c|c|c|}
\hline Cost Item & Conventional School & $\begin{array}{c}\text { Engineering-Medicine } \\
\text { School }\end{array}$ \\
\hline Information Technology & $\$ 500,000$ & $\$ 500,000 \times 1.1=\$ 550,000$ \\
\hline \multicolumn{3}{|l|}{ Faculty } \\
\hline Basic Science & $\$ 67,932 \times 65=\$ 4,415,580$ & $\$ 4,415,580$ \\
\hline Clinical & $\$ 249,000 \times 195=\$ 48,555,000$ & $\$ 48,555,000$ \\
\hline Engineering & 0 & $\$ 97,023 \times 13=\$ 1,261,299$ \\
\hline Staff & $\$ 60,000 \times 100=\$ 6,000,000$ & $\$ 6,000,000$ \\
\hline Subtotal & $\$ 59,470,580$ & $\$ 60,781,879$ \\
\hline Education Building & ( $\$ 80$ million loan, $5 \%$ interest) & $\begin{array}{l}\text { (\$92 million loan, } 5 \% \\
\text { interest) }\end{array}$ \\
\hline (Amortized to annual cost) & $\$ 5,676,196$ & $\$ 6,527,626$ \\
\hline Total & $\$ 65,146,776$ & $\$ 67,309,505$ \\
\hline Nation-wide total & $\$ 65,146,776 \times 1,496=$ & $\$ 67,309,505 \times 1,496$ \\
\hline (total students) & $\$ 97,459,576,896$ & $\$ 100,695,019,480$ \\
\hline Differential: & & $+\$ 3,235,442,584$ \\
\hline
\end{tabular}

\section{Faculty costs: conventional vs. engineering-medicine}

On the faculty equation, the engineering-medicine curriculum will obviously require a new set of engineering faculty, in addition to the medical faculty. [22-24]. In terms of number of faculty relative to number of students, currently there is no standard to follow and there is a wide variation among medical schools in the US. A review of published literature revealed some interesting findings. Harvard University, ranked No. 1 Best Research-oriented Medical School by the U.S. News \& Report this year, has a full-time faculty to student ratio of 13.3:1. Other medical schools on this list showed that University of Pennsylvania (ranked No. 3), University of Michigan (ranked No. 11), University of North Carolina at Chapel Hill (ranked No. 22), Case Western University (ranked No. 25), Brown University (ranked No. 35), and Medical College of Wisconsin (ranked No. 55), Drexel University (ranked No. 82), and University of Central Florida (ranked No. 88) have full-time faculty to student ratio of 4.7:1, 2.6:1, 1.8:1, 3.0:1, 1.4:1, 1.91, $0.6: 1$, and $0.8: 1$, respectively [25]. Obviously, there is no good correlation between the faculty to student ratio and the quality of education per se, but the better schools tend to have at least a 1.3:1 ratio. It is not clear, however, to what extent these faculty members participate in direct medical student teaching. Thus the exact direct teaching contribution of these faculty members is not defined. For the purpose of this analysis, we will use a ratio of $1.3: 1$. Thus for the full capacity of student body of 200, we will aim for the faculty members of 260, including both basic science and clinical faculty, for the conventional medical school calculation. In terms of ratio of basic science to clinical faculty, there is also no standard. We will make the assumption of $25 \%$ basic science and $75 \%$ clinical faculty. Thus we will need 65 basic science and 195 clinical faculty members for a conventional medical school. Using salary data from University of Florida, the average annual salary pooled from 18 specialties of clinical faculty was approximated to be $\$ 249,000$ [22]. For the engineering-medicine school, we will calculate additional 13 engineering faculty members (of Associate Professor level), one for each of the engineering subjects depicted in the curriculum in the section above. According to a higher education survey, the average biological science and engineering faculty annual salary (2015-16) at the Associate Professor level are $\$ 67,932$, and $\$ 97,023$, respectively [24]. Thus an additional $\$ 1,261,299$ annual cost for engineering faculty members will be calculated into the engineering-medicine equation. The detailed calculation of cost will be depicted in Table 1 .

Administration costs: convention vs. engineering-medicine. For this item, the assumption is that there will be no increase of cost between conventional and the engineering-medicine schools. We estimated that 100 staff members are needed (Table 1).

Comparison total costs between conventional and the engineeringmedicine school: According to recent (2015) data, the total number of medical graduates per class in the United States is 18,705 [26]. This total graduate number multiplied by 4 and then divided by 50 will give a factor of 1,496, which will be used to multiply by the annual cost of a 50-student-per-class school to obtain the nation-wide total cost (Table 1). Finally, we determined by extrapolation that the engineeringmedicine school, if operated for the entire United States, will cost $\$ 3,235,442,584$ ( $\$ 3.235$ billion) more than the conventional medical school annually (Table 1). Having determined the cost differential, we now move to examine the effectiveness.

\section{Effectiveness Analysis}

As we did for the cost analysis, we will also define the following analytical assumptions: Effectiveness will be defined by the healthcare saving in dollar terms, whether it is accomplished by increased efficiency or by reducing cost $[17,18]$.

With the assumptions set, the next step will be data collection. Since circulatory, musculoskeletal, respiratory, and endocrine group of diseases, along with ill-defined conditions, account for the top 5 disease groups where the US health system is spending its largest sum of money, it is logical to collect as much data in relation to these diseases, for the purpose of this cost-effectiveness analysis. In 2012, one organization estimated that US national expenditures were estimated to be $\$ 241$ Billion, \$186 Billion, \$157 Billion, and \$138 Billion, for circulatory, musculoskeletal, respiratory, and endocrine diseases, respectively. [27].

Healthcare System Savings on Musculoskeletal Disease: Geriatric hip fracture is a rather common medical problem among senior citizens $[28,29]$. It will be prudent to consider ways to improve clinical outcomes and to reduce cost in these clinical encounters. Utilizing the engineering concept of integration, an implementation of integrated, collaborative, standard treatment protocol called the Geriatric Hip Fracture Clinical Pathway (GHFCP) resulted in improvement of clinical outcomes and in reduction of provider manpower utilized for each fracture occurrence. Specifically, the length of hospital stays in the surgery and recovery were reduced by 6.1 days and 14.2 days respectively (an overall $50 \%$ reduction). In addition, the post-operative pneumonia infection rate was reduced from $1.25 \%$ to $0.25 \%$ (a $1 \%$ reduction) [29]. According to a study, the medical expenditures for osteoporotic fractures in the US in 1995 was estimated to be $\$ 13.8$ billion, with about $\$ 8.5$ billion spent for hip fractures, for which the hospital costs were about 65\% [30]. Thus, the total costs of in-patient hip fracture care will be about $\$ 5.5$ billion each year. For a $50 \%$ reduction of hospital stay, the healthcare saving could be near $\$ 2.75$ billion annually for the US, even without counting the potential saving from reduction of post-operative pneumonia by this new pathway, assuming no increase of cost in the implementation of this integrated system of GHFCP.

Healthcare System Savings for Diabetes: Diabetes is a major endocrine disease where the engineering principle of integration could help reducing the cost, which was estimated between $\$ 100$ and $\$ 245$ billion in the US for the year of 2012 [27, 31, 32]. The estimated expenditure in physician office visits is $9 \%$, accounting for $\$ 15.5$ billion ( $0.09 \mathrm{X} \$ 175$ billion, which is used as the mid figure between $\$ 100$ and $\$ 245$ billion). Among the common non-acute diabetes complications and their required corresponding primary and specialty physician office visits are: high blood pressure and stroke (primary 
care \& neurology), hyper- and hypo-glycemia (endocrinology), heart diseases (cardiology), neuropathy (dermatology \& podiatry), retinopathy (ophthalmology), gastroparesis (gastroenterology), and kidney malfunction (nephrology) [33]. If we use a conservative estimation that on average a patient with diabetes will encounter $50 \%$ of these complications, then a patient would need to see 5 different physicians to control their disease co-morbidities. Without integrative care, these patients would need to set up appointment and commute to see 5 different physicians in 5 separated times. During physician office visits, each of these 5 physicians would need to take a history, perform physician examinations, order diagnostic tests, and prescribe appropriate treatments. Engineering integration could help improve effectiveness by transforming the care delivery to an integrated diabetes center. Like that of a cancer center where patients with cancer will get all the necessary and coordinated cancer-related care in one place, an innovative diabetes center will provide all the necessary and coordinated diabetes-related care in one place. Logistically, patients with diabetes will be able to make appointments with all 5 physician office visits in an integrated manner. During the coordinated office visits, the patient will first see a primary care physician, who will take a comprehensive history and physical examination, order common laboratory tests, and prescribe non-specialty treatments, then send the patient to be seen by the first specialty physician within the diabetes center in the same day. The first specialty physician will then utilize the medical record completed by the primary care physician (that contains most essential history, physical findings, lab results, and treatments), perform a focused specialty-related physician examination, order specialtyrelated lab tests and treatments, and then send the patient to the second specialty physicians also located in the same diabetes center, and so on down to the $5^{\text {th }}$ physician. This kind of engineering-based integrative care will not only save patients' time for arranging and commuting to 5 physician visits, it will importantly, also save physicians' manpower. If we conservatively estimate that on the average $30 \%$ of a physician visit is spent in taking the history, we will save equivalent physician manpower of 1.2 office visit ( 0.3 visit $X 4)$ for each diabetes patient we care for, or overall a physician manpower saving of $24 \%((0.3 \mathrm{X} 4) / 5)$. Extrapolating this saving to a nation-wide equation, we could potentially save $\$ \mathbf{\$ 3 . 7 2}$ billion ( $\$ 15.5$ billion $\mathrm{x} 0.24$ ) annually, assuming no cost increase will be needed to implement this integrated care system. Other potential saving from this integrated diabetes care will be the reduction of the expenditures on duplicated lab tests. In addition, a societal benefit will be the reduction of non-productive time and energy of the diabetes patients. If we assume each of the 24 million diabetic patients in the US will have one annual visit to their respective physicians [34], and if we conservatively estimate that each physician visit will cost a patient non-productive time of 1.25 hour ( 30 minute in commute, 45 minutes in office visit), the total annual cost will be 6.25 hours. On the other hand, the integrated visit will cost non-productive time of 3.35 hours (30 minutes in commute, 171 minutes or 2.85 hour $(45+(45 \mathrm{X} 0.7 \mathrm{X} 4)$ ) in office visits), we will potentially save 69.6 million hours of productive time (6.25 - 3.35) X 24 million) for diabetes patients annually. Using a minimum wage of $\$ 15 /$ hour, we could easily save the US society $\$ \mathbf{1 . 0 4}$ billion annually. Other potential savings to the society include reduction of expenses on gasoline, automobile repair and depreciation.

Healthcare System Savings for Heart Disease: Cardiovascular diseases as a group has the second highest costs of healthcare in the US. Among this group of diseases, heart failure has a substantial cost: In 2012, the direct cost of heart failure in the US was $\$ 21$ billion, $80 \%$ of which was the cost of hospitalization, accounting for $\$ 16.8$ billion annually [35]. The mean cost of a single congestive heart failure readmission is $\$ 13,000$, with a $25.1 \%$ readmission rate [36]. In a study published in
2011, healthcare systems in the State of Maine leveraged an integrated care system, which was able to reduce the heart failure readmission by $5.83 \%$ (from $18.5 \%$ to $12.67 \%$ ) [37]. If readmission accounts for $25 \%$ of total hospital admissions of heart failure, this integrated system could potentially reduce the cost of hospital readmission of congestive heart failure by $\$ 245$ million ( $\$ 16.8$ billion X 0.25 X 0.0583 ) annually in the US, assuming there is no increase cost in implementing this integrated heart failure care system.

\section{Cost-effectiveness Ratio}

$\{$ Ratio $\}=($ Cost of Engineering-Medicine - Cost of Conventional School)/(Effectiveness of Engineering-Medicine - Effectiveness of Conventional School $)=(\$ 3.235$ billions $) /(\$ 2.75+\$ 3.72+1.04+$ $\$ 0.245)$ billion $=\$ 3.235$ billion $/ \$ 7.755$ billion $=0.42$.

According to the above calculation with the said assumptions, the engineering-medicine school would be cost-effective.

\section{One-way sensitivity analysis}

- Assuming there is a $30 \%$ reduction on the side of effectiveness due to increased cost in implementing the clinical integration: (Ratio) $=$ $\$ 3.235$ billion $/(\$ 7.755$ billion X 0.70$)=3.325 / 5.4285=0.61$ Costeffectiveness is still achieved.

- For $75 \%$ efficiency of the physician effectiveness: $\{$ Ratio $\}=\$ 3.235$ billion $/(\$ 7.755$ billion X 0.75) $=3.325 / 5.816=0.57$ With $75 \%$ efficiency, the engineering-medicine school remains highly costeffective.

- For $50 \%$ efficiency of the physician effectiveness: $\{$ Ratio $\}=\$ 3.235$ billion/(\$7.755 billion X 0.5) 3.325/3.8775 $=0.86$ Even with $50 \%$ efficiency, Engineering-medicine remains cost-effective.

- Breakeven \% efficiency of the physician effectiveness (Ratio = 1) $1.0=\$ 3.235$ billion $/(\$ 7.755$ billion X Breakeven \%) Breakeven point $=\$ 3.235 / \$ 7.755=42.87 \%$ physician effectiveness.

- For $30 \%$ efficiency of the physician effectiveness: $\{$ Ratio $\}=\$ 3.235$ billions/( $\$ 7.755$ billions X 0.3$)=1.39$ With this low $25 \%$ efficiency, engineering-medicine will no longer be cost-effective.

\section{Two-way sensitivity analysis}

Assuming 75\% efficiency of the physician effectiveness: Assuming also the cost of engineering-medicine school will be more than initially projected: The IT cost is $20 \%$ above the conventional medical school, staff requirement for the engineering-medicine school is increased by $10 \%$, and the engineering faculty requirement is increased by $30 \%$ to 17 (Table 2). With the above modifications, we still find engineeringmedicine school to be cost-effective, with the ratio calculated to be 0.82 [ $\$ 4.788$ billion/( $\$ 7.755$ billion X 0.75)].

Assuming the efficiency of physician effectiveness is reduced further to $50 \%$ and the costs are also increased the same amount as above: $\{$ Cost-effectiveness Ratio $\}=\$ 4,788$ billion $/(\$ 7.755 \mathrm{X} 0.50)$ billion $=1.23$. Now the engineering-medicine school is no longer costeffective.

\section{Summary}

Through data collected or estimated for three major diseases where engineering principles could save healthcare dollars, we showed, based on limited available data, that engineering-medicine education has the potential to help generate healthcare savings and it could be costeffective from the societal perspective. This analysis revealed relative 
Table 2. Two-way Sensitivity Analysis with increased costs in Engineering-Medicine School \& reduced efficiency to $75 \%$.

\begin{tabular}{|l|l|l|}
\hline Cost Item & Conventional School & $\begin{array}{l}\text { Engineering-Medicine } \\
\text { School }\end{array}$ \\
\hline Information Technology & $\$ 500,000$ & $\$ 500,000 \times 1.2=\$ 600,000$ \\
\hline Faculty & & \\
\hline Basic Science & $\$ 67,932 \times 65=\$ 4,415,580$ & $\$ 4,415,580$ \\
\hline Clinical & $\$ 249,000 \times 195=\$ 48,555,000$ & $\$ 48,555,000$ \\
\hline Engineering & 0 & $\$ 97,023 \times 17=\$ 1,649,391$ \\
\hline Staff & $\$ 60,000 \times 100=\$ 6,000,000$ & $\$ 60,000 \times 110=\$ 6,600,000$ \\
\hline Subtotal & $\$ 59,470,580$ & $\$ 61,819,971$ \\
\hline Education Building & $(\$ 80$ million loan, $5 \%$ interest) & $\mathbf{\$} \$ 2$ million loan, 5\% interest) \\
\hline (Amortized to annual cost) & $\$ 5,676,196$ & $\$ 6,527,626$ \\
\hline Total & $\$ 65,146,776$ & $\$ 68,347,597$ \\
\hline Nation-wide total & $\$ 65,146,776 \times 1,496=$ & $\$ 68,347,597 \times 1,496$ \\
\hline (total students) & $\$ 97,459,576,896$ & $\$ 102,248,005,112$ \\
\hline Differential: & & $+\$ 4,788,428,216$ \\
\hline
\end{tabular}

$\{$ Cost-effectiveness Ratio $\}=\$ 5,013$ billion $/(\$ 8 \times 0.75)$ billion $=0.84$ (still cost-effective)

insensitivity to variation of efficiency of physician effectiveness alone in a one-way sensitivity method, but demonstrated relative sensitivity to combined variation of cost and efficiency of physician effectiveness in a two-way sensitivity method.

\section{Conclusion}

Having determined its potential cost-effectiveness, engineeringmedicine education should be appropriate to conduct in a small segment of undergraduate medical schools as a proof of concept project. If successful, it could prove to be a good model for future medical education reform. Since the cost-effectiveness is demonstrated from a societal perspective and not necessarily from a medical college (institutional) perspective, the additional cost for training these engineering-physicians should probably be bored by society which would stand to benefit from this novel path of education.

\section{Conflict of interest}

None.

\section{Submission declaration}

This manuscript in any form has not been submitted to any other journal for consideration. This work is in part supported by Dr. Orville J. Stone Endowed Professorship (University of Illinois College of Medicine, Chicago, IL USA).

\section{References}

1. OECD health statistics 2014. How does the United States compare? [www.oecd.org/ unitedstates] accessed September 13, 2015

2. Mirror, mirror on the wall, 2014 update: How the U.S. health care system compares internationally. [www.commonweathfund.org/publications] accessed September 13, 2015

3. Plunkett-Rondeau J, Hyland K, Dasgupta S (2015) Training future physicians in the era of genomic medicine: trends in undergraduate medical genetic education. Genet Med. 17:927-934. [Crossref]

4. Moskowitz A, McSparron J, Stone DJ, Celi LA (2015) Prepare a new generation of clinicians for the era of Big Data. Harvard Medical Student Review.

5. Day J, Davis J, Riesenberg LA, Heil D, Berg K, et al. (2015) Integrating sonography training into undergraduate medical education: A study of the previous exposure of one institution's incoming residents. J Ultrasound Med. 34:1253-1257. [Crossref]

6. Fung K (2015) Otolaryngology--head and neck surgery in undergraduate medical education: advances and innovations. Laryngoscope 125 Supp1 2: S1-14. [Crossref]
7. Duda GN, Grainger DW, Frisk ML, Bruckner-Tuderman L, Carr A, et al. (2014) Changing the mindset in life sciences toward translation: a consensus. Sci Transl Med 6: p. $254 \mathrm{~cm} 1$ [Crossref]

8. Rietschel ET, Bruckner-Tuderman L, Schutte G, Wess G (2015) Translation. Moving medicine forward faster. Sci Transl Med 7: p.277ed2

9. Core measurement needs for better care, better health, and lower costs: Counting what counts-workshop summary. Institute of Medicine. June 24, 2013.

10. Accelerating change in medical education. American Medical Association.

11. Chan LS (2016) Building an engineering-based medical college: Is the timing right for the picking? Med Sci Edu 26:185-90.

12. Transforming undergraduate education in engineering. American Society for Engineering Education.

13. Reid PP, et al. Building a better delivery system: A new engineering/health care partnership. National Academies Press, 2005.

14. Wilensky G (2016) Changing Physician Behavior Is Harder Than We Thought. JAMA 316: 21-22. [Crossref]

15. EnMed. Engineering \& Medicine (2017) Texas A \& M University.

16. Carle Illinois College of Medicine. (2017) The first engineering-based college of medicine.

17. Drummond MF, Sculpher MJ, Claxton K, Stoddart GL, Torrance GW (2015) Methods for the economic evaluation of health care programmes. Oxford University Press.

18. Muennig P and Bounthavong M. Cost-effectiveness analysis in health: a practical approach. Third Ed. Jossey-Bass. San Francisco, CA: 2016

19. New Building. School of Medicine \& Health Sciences. UND: University of North Dakota. [http://www.med.und.edu/construction/] accessed December 5, 2016

20. Six-story Medical School Building Rise in Camden. Cooper Medical School of Rowan University. [http://www.rowan.edu/coopermed/about/news/] accessed December 5, 2016

21. New Buildings. [https://www.aamc.org] accessed December 5, 2016

22. University of Florida College of Medicine Faculty Compensation Plan. July 1, 2013 to June 30, 2014. [https://connect.ufl.edu/comfs/ComPlan/] accessed March 9, 2016

23. Biomedical Engineers: Occupational outlook handbook. US Bureau of Labor Statistics. [www.bls.gov] accessed July 5, 2016

24. Tenured/Tenure-track faculty salaries. HigherEd Jobs. [https://www.higheredujobs. com/salary/SalaryDisplay.cfm?SurveyID=37] accessed December 7, 2016

25. U.S. News \& World Report. Education. [http://grad-schools.usnews rankingsandreviews.com/] accessed December 7, 2016

26. Total number medical graduates. KFF.org. [http://kff.org/other/state-indicator/totalmedical-school-graduates/?currentTimeframe $=0$ ] accessed December 10, 2016

27. How much does the U.S. spend to treat different diseases? Peterson-Kaiser Health System Tracker. [http://www.healthsystemtracker.org/chart-collection/how-muchdoes-the-u-s-spend-to-treat-different-diseases/] accessed December 4, 2016

28. Lau TW, Fang C, Leung F (2013) The Effectiveness of a Geriatric Hip Fracture Clinica Pathway in Reducing Hospital and Rehabilitation Length of Stay and Improving ShortTerm Mortality Rates. Geriatr Orthop Surg Rehabil 4: 3-9. [Crossref]

29. Lau TW, Fang C, Leung F (2016) The effectiveness of a multidisciplinary hip fracture care model in improving the clinical outcome and the average cost of manpower.

30. Ray NF, Chan JK, Thamer M, Melton J (1997) Medical expenditures for the treatment of osteoporotic fractures in the United States in 1995: Report from the National Osteoporosis Foundation. J Bone Mineral Res 12: 24-35. [Crossref]

31. The cost of diabetes. American Diabetes Association. [http://www.diabetes.org/ advocacy/news-events/cost-of-diabetes.html] accessed December 4, 2016

32. Grant $\mathrm{P}$ and Chika-Ezeriche I. Evaluating diabetes integrated care pathway. Practical diabetes. 2014; 31:319-22.

33. Complications. American Diabetes Association. [http://www.diabetes.org/living-withdiabetes/complications/] accessed December 4, 2016 
Chan LS (2018) Engineering-medicine as a transforming medical education: A proposed curriculum and a cost-effectiveness analysis

34. Diabetes prevalence expected to double in next 25 years. American Diabetes Association. [http://www.diabetes.org/newsroom/press-releases/2009/diabetesprevalence-expected-to-double.html] accessed December 4, 2016

35. What is the cost of heart failure on the economy? Economic Impact. [http://www. heartfailure.com/hcp/heart-failure-cost.jsp] accessed December 4, 2016
36. Six (6) stats on the cost of readmission for CMS-tracked conditions. Becker's Infection control \& clinical conditions. [http://www.beckershospitalreview.com/quality/6-stats-onthe-cost-of-readmission-for-cms-tracked-conditions.html] accessed December 4, 2016

37. Cawley J, Grantham CC (2011) Building a System of Care: Integration across the Heart Failure Care Continuum. Perm J 15: 37-42. [Crossref]

Copyright: $\mathbb{C} 2018$ Chan LS. This is an open-access article distributed under the terms of the Creative Commons Attribution License, which permits unrestricted use, distribution, and reproduction in any medium, provided the original author and source are credited. 